Short Communication

Animal Genetics

\title{
The molecular cytogenetic characterization of Conopophaga lineata indicates a common chromosome rearrangement in the Parvorder Furnariida (Aves, Passeriformes)
}

Thays Duarte de Oliveira ${ }^{1}$ id, Rafael Kretschmer ${ }^{2}$ (iD, Natasha Ávila Bertocchi' (iD, Patricia C.M. O'Brien ${ }^{3}$, Malcolm A. Ferguson-Smith ${ }^{3}$, Analía del Valle Garnero ${ }^{4}$ iD, Edivaldo Herculano Correa de Oliveira ${ }^{5,6}$ (iD and Ricardo José Gunski ${ }^{4}$ in

${ }^{1}$ Universidade Federal do Rio Grande do Sul (UFRGS), Programa de Pós-Graduação em Biologia Animal, Porto Alegre, RS, Brazil.

${ }^{2}$ Universidade Federal do Rio Grande do Sul (UFRGS), Programa de Pós-Graduação em Genética e Biologia Molecular, Porto Alegre, RS, Brazil.

${ }^{3}$ University of Cambridge, Department of Veterinary Medicine, Cambridge, United Kingdom.

${ }^{4}$ Universidade Federal do Pampa (UNIPAMPA), Programa de Pós-Graduação em Ciências Biológicas, São

Gabriel, RS, Brazil.

${ }^{5}$ Instituto Evandro Chagas, Seção Meio Ambiente (SAMAM), Ananindeua, PA, Brazil.

${ }^{6}$ Universidade Federal do Pará, Belém, Instituto de Ciências Exatas e Naturais, Belém, PA, Brazil.

\begin{abstract}
Cytogenetic analyses of the Suboscines species are still scarce, and so far, there is no karyotype description of any species belonging to the family Conopophagidae. Thus, the aim of this study is to describe and analyze the karyotype of Conopophaga lineata by chromosome painting using Gallus gallus (GGA) probes and to identify the location of the 18/28S rDNA cluster. Metaphases were obtained from fibroblast culture from two individuals of $C$. lineata. We observed a diploid number of $2 n=78$. GGA probes showed that most ancestral syntenies are conserved, except for the fission of GGA1 and GGA2, into two distinct pairs each. We identified the location of 18S rDNA genes in a pair of microchromosomes. The fission of the syntenic group corresponding to GGA2 was observed in other Furnariida, and hence may correspond to a chromosomal synapomorphy for the species of Parvorder Furnariida.
\end{abstract}

Keywords: Birds, avian chromosomal evolution, chromosomes, rDNA.

Received: January 27, 2020; Accepted: April 12, 2020.

The order Passeriformes encompasses approximately 5700 species, equivalent to $60 \%$ of existing birds, and besides their large diversity, they can also be considered a cosmopolitan group, thus becoming the focus of different studies. The order encompasses two large Suborders - Oscines and Suboscines (Ericson et al., 2003, 2014). The process of song learning is the main distinction between Oscines and Suboscines: Oscines are characterized by complex vocalizations, which are often learned through imitation. On the other hand, Suboscines have less complex vocal organs, and their songs do not seem to be learned by imitation (Raikow and Bledsoe, 2000). Suboscines are traditionally divided into two infraorders - Tyrannides (272 genera), endemic to the New World, and Eurylaimides (12 genera), which are widely distributed in the Old World (Selvatti et al., 2015).

Send correspondence to Ricardo José Gunski. Universidade Federal do Pampa (UNIPAMPA), Programa de Pós-Graduação em Ciências Biológicas, Av. Antonio Trilha, 1847, São Gabriel, 97300162, RS, Brazil. E-mail: ricardogunski@ unipampa.edu.br.
Tyrannides are divided into the Parvorders - Furnariida and Tyrannida (Selvatti et al., 2015). The species Conopophaga lineata (CLI), the focus of this study, belongs to the Conopophagidae family, which is included in the Parvorder Furnariida.

Most cytogenetic studies in Passeriformes have used classical approaches and, among birds, this is the order with the largest number of species analyzed (Kretschmer et al., 2018a). Of the twenty species of this order examined by molecular genetics so far, six belong to the Suborder Suboscines: Elaenia spectabilis, Pitangus sulphuratus, Serpophaga subcristata and Satrapa icterophrys (Tyrannida Tyrannidae), Synallaxis frontalis and Glyphorynchus spirurus (Furnariida - Furnariidae) (Guttenbach et al., 2003; Derjusheva et al., 2004; Itoh and Arnold, 2005; Kretschmer et al., 2015; Santos et al., 2017; Rodrigues et al., 2017; Kretschmer et al., 2018b; Ribas et al., 2018). Using as reference the putative ancestral karyotype of birds (Griffin et al., 2007), all species analyzed by chromosome painting with 
Gallus gallus probes (GGA) have presented conservation of ancestral macrochromosomes, except for ancestral pair 1which corresponds to two pairs representing a synapomorphy for Passeriformes - and pair 2, which has undergone fission in Satrapa icterophrys (Parvorder Tyrannida), Synallaxis frontalis and Glyphorynchus spirurus (Parvorder Furnariida) (Rodrigues et al., 2017; Kretschmer et al., 2018b; Ribas et al., 2018). Additionally, the use of $18 \mathrm{~S}$ rDNA probes has revealed that the number and distribution of NORs varies from 1-3 pairs in Passeriformes (Kretschmer et al., 2014, 2015; Rodrigues et al., 2017).

Despite these data, information on events occurring during the karyotype evolution of Passeriformes is still fragmentary, as observed in most groups of birds. In this sense, studies involving species from basal clades are important to reconstruct the sequence of rearrangements arising during Passeriformes diversification. Considering that Conopophagidae represents one of the most basal lineages of passerines (Selvatti et al., 2015), a detailed study of one species of this family may shed some light on the chromosome evolution of Passeriformes. Hence, we describe here for the first time the karyotype of a species belonging to this family, the rufous gnateater (Conopophaga lineata).

The protocols were approved by the Committee of Ethics on the use of Animals (CEUA- Universidade Federal do Pampa, 026/2012), and SISBIO (Permission Number: 101 33860-4). Skin biopsies were collected from two females of $C$. lineata in Porto Vera Cruz and São Gabriel (Rio Grande do Sul, Brazil), and used for cell culture, following Sasaki et al. (1968), with modifications. In this process, cells were dissociated with collagenase type IV (Sigma) and grown in DMEM medium supplemented with fetal bovine serum $(20 \%)$. Chromosome preparations were obtained after exposure to colcemid $\left(1 \mathrm{~h}, 37{ }^{\circ} \mathrm{C}\right)$, hypotonic treatment $\left(0.075 \mathrm{M} \mathrm{KCl}, 15 \mathrm{~min}, 37^{\circ} \mathrm{C}\right)$ and methanol/acetic acid (3:1). fixative

Fluorescence in situ hybridization (FISH) experiments were performed using whole chromosome probes from $\mathrm{Gal}$ lus gallus (GGA 1-10), obtained by flow cytometry at the Cambridge Resource Centre for Comparative Cytogenetics, (Cambridge, UK), amplified and labeled with biotin by DOP-PCR. Hybridizations were carried out according to Oliveira et al. (2010). Detection was performed with the use of Streptavidin-CY3 (Invitrogen). 18S rDNA probe fragments were labeled with digoxigenin by Nick Translation (Nick Translation Kit, Roche) and detected with Anti-Digoxigenin-Rhodamine, following the manufacturer's instructions, slide preparation, hybridization and washing were performed according to Daniels and Delany (2003).

Approximately 30 mitotic metaphases from each specimen were analyzed in order to determine the diploid number, chromosome morphology and confirm FISH experiments. Metaphases were analyzed in an epifluorescence light microscope (Imager Z2, Zeiss, Germany), and the images were acquired with the software Axiovision 4.8 (Zeiss, Germany).
The diploid number of $C$. lineata is 78 . Pairs 1 to 7 are acrocentric, except for pair 4, which is submetacentric. The other autosomal chromosomes are telocentric, while the $\mathrm{Z}$ sex chromosome is submetacentric and $\mathrm{W}$ sex chromosome possibly is a telocentric microchromosome (Figure 1).

GGA probes 1-10 produced 13 different signals, revealing chromosome rearrangements. Most of the ancestral macrochromosomes are conserved in $C$. lineata, except for GGA1 and GGA2, which are fissioned in two pairs each. GGA 4 probe hybridized to two chromosome pairs, as in the putative bird ancestral karyotype. GGA3 and 5-10 hybridized to only a single pair each, revealing conserved syntenies. In addition, CLI 5 is the result of a fusion between a segment of GGA2 and an unidentified chromosome, possibly a microchromosome (Figures 2A,B and 3).

The diploid number observed, $2 \mathrm{n}=78$, is found in most bird species and is similar to the hypothetical bird ancestor (80 chromosomes) (Griffin et al., 2007). It was possible to observe that the first and second pairs have a similar size, differently from most of Passerines studied so far (Kretschmer et al., 2014; Santos et al., 2017), indicating an additional fission in Conopophaga lineata.

In fact, FISH results (Figure 2) revealed that GGA 1, 2 and 4 probes hybridized on two chromosome pairs each, whereas all other probes hybridized to only one chromosome pair each. While GGA1 fission is commonly found in Passeriformes and considered a synapomorphy for this group (Kretschmer et al., 2015; Santos et al., 2017), the hybridization of GGA4 to two chromosome pairs - CLI4 and CLI13 (Figure 2D) - is common to most birds, representing the ancestral state, and hence, in G. gallus this pair is the result of the fusion of two chromosomes of the putative avian ancestral karyotype (PAK), PAK4 and PAK10 (Griffin et al., 2007, Kretschmer et al., 2018a). Additionally, centric fission of GGA1 is also observed in species of the orders Strigiformes, Psittaciformes, Falconiformes, and Accipitriformes (Guttenbach et al., 2003; Oliveira et al., 2005, 2008; Nanda et al., 2006, 2007).

Interestingly, the fission of GGA2, into two chromosomes in C. lineata (CLI1 and CLI5q) (Figure 3), is atypical for Passeriformes; normally GGA2 is conserved and corresponds to the largest pair (Table 1) (Kretschmer et al., 2014, 2015; Santos et al., 2017). Moreover, the centric fission of GGA2 was observed in other Suboscines species, belonging to parvorder Furnariida - Synallaxis frontalis (Kretschmer et al., 2018b) and Glyphorynchus spirurus (Ribas et al., 2018)

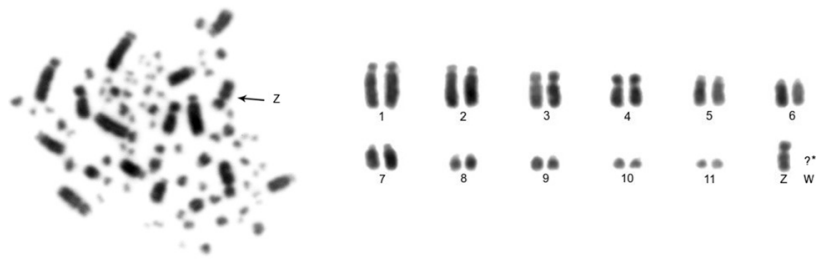

Figure 1 - Metaphase and partial karyotype of a female specimen of Conopophaga lineata. *It was not possible to identify the W sex chromosome. 

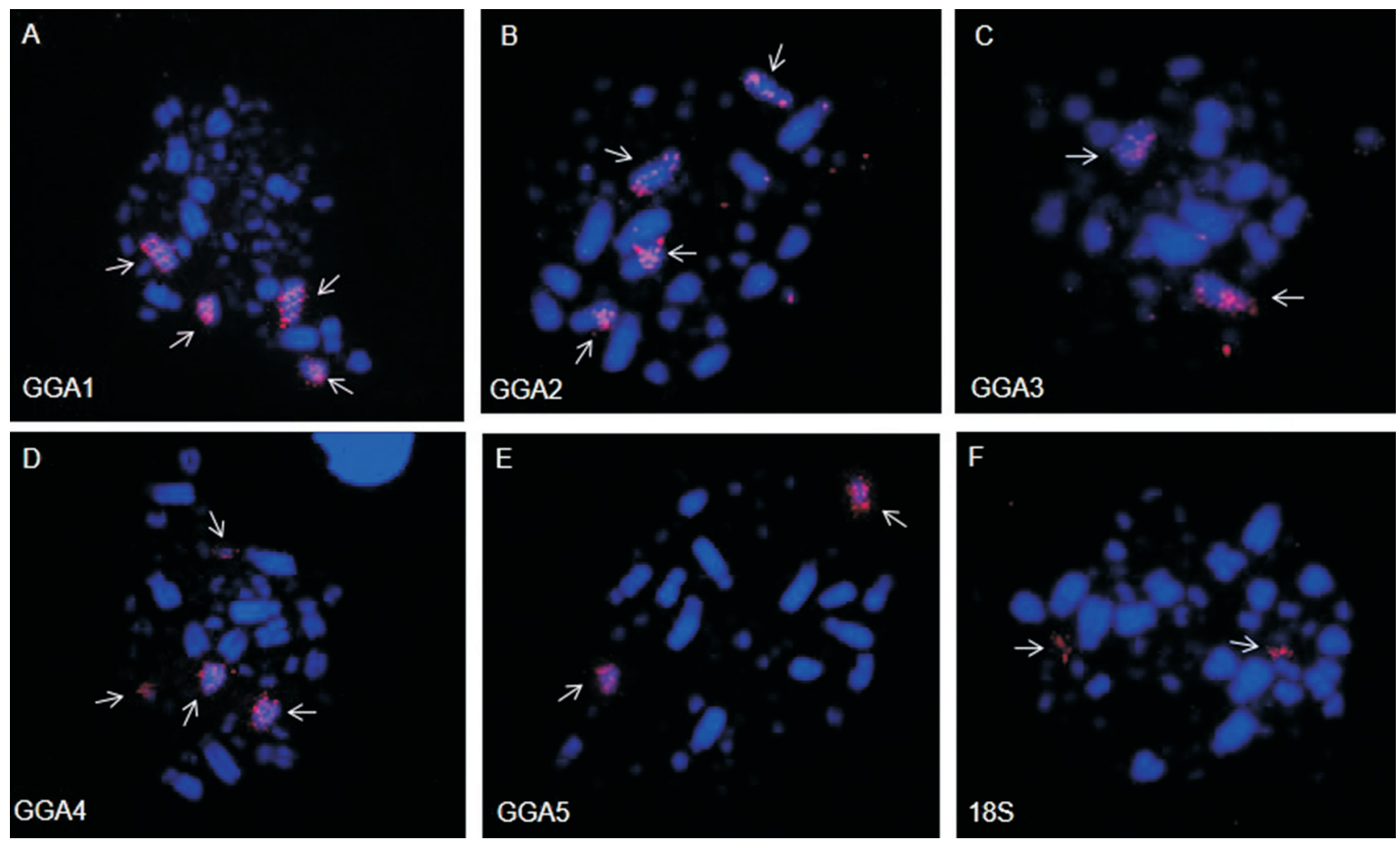

Figure 2 - Representative FISH experiments with GGA1 (A), GGA2 (B), GGA3 (C), GGA4 (D), GGA5 (E) and 18S rDNA probes (F) in metaphases of Conopophaga lineata. Arrows indicate the homologous chromosomes to the probes used.

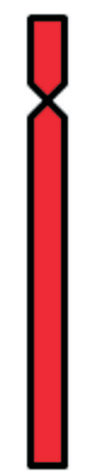

1

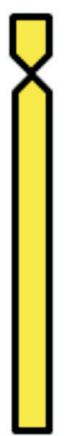

2

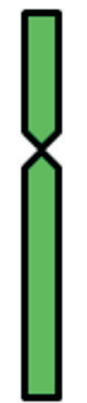

3

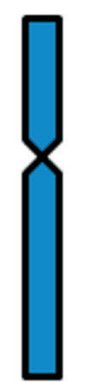

4

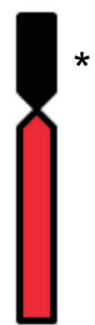

5

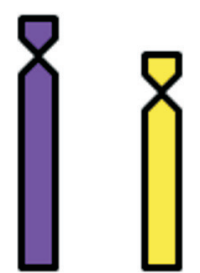

6

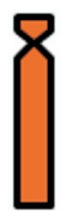

8

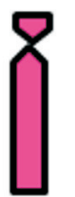

9

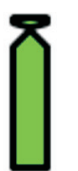

10

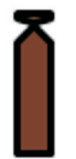

11

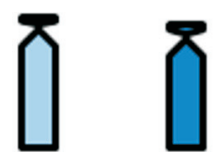

12

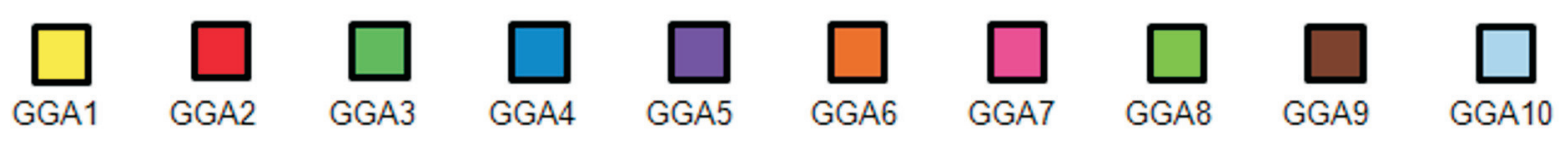

Figure 3 - Homology map of Conopophaga lineata with Gallus gallus (GGA) probes indicated by color. *Not hybridized segment with any GGA probes used.

-, and parvorder Tyrannida - Satrapa icterophrys (Rodrigues et al., 2017), which also shows pairs 1 and 2 with similar sizes, as in C. lineata. Hence, this fission explains the minimum size difference between the first and second pairs in other Suboscines species in which only classical cytogenetic data (Giemsa staining and chromosome banding) are available, such as Sittasomus griseicapillus, Lepidocolaptes an- gustirostris (Dendrocolaptidae) and Pyriglena leucoptera, Dysithamnus mentalis (Formicariidae) - all of them are members of Parvorder Furnariida (Ledesma et al., 2002; Moyle et al., 2009; Barbosa et al., 2013; Kretschmer et al., 2018b). Consequently, GGA2 fission in species of parvorder Furnariida and in Satrapa icterophrys of parvorder Tyrannida may be indicative of convergent evolution (Table 1). 
Table 1 - Rearrangements in putative avian ancestral karyotype homologous segments (PAK1-10) in Suboscines species.

\begin{tabular}{|c|c|c|c|}
\hline Parvorders & Species & Rearrangements & References \\
\hline Tyrannida & Elaenia spectabilis & fission PAK1 (ESP2 and 5) & Kretschmer et al., 2015 \\
\hline Tyrannida & Pitangus sulphuratus & fission PAK1 (PSU3 and 5) & Rodrigues et al., 2018 \\
\hline Tyrannida & Serpophaga subcristata & fission PAK1 (SSU3 and 5) & Rodrigues et al., 2018 \\
\hline Tyrannida & Satrapa icterophrys & fission PAK1 (SIC2 and 5) fission PAK2 (SIC3 and 7) & Rodrigues et al., 2018 \\
\hline Furnariida & Synallaxis frontalis & fission PAK1 (SFR1 and 5) fission PAK2 (SFR3 and 7) & Kretschmer et al., 2018b \\
\hline Furnariida & Glyphorynchus spirurus & fission PAK1 (GSP3 and 4) fission PAK2 (GSP2 and 5) & Ribas et al., 2018 \\
\hline Furnariida & Conopophaga lineata & fission PAK1 (CLI2 and 7) fission PAK2 (CLI1 and 5q) & Present study \\
\hline
\end{tabular}

In addition to the fission of GGA2, we have identified that pair 5 of $C$. lineata was formed from a fusion between one of the segments originated from the GGA2 fission and a microchromosome (Figure 3).

Despite the fact that these rearrangements have been observed in a species belonging to the basal family Conopophagidae, the localization of ribosomal clusters in a pair of microchromosomes, corresponds to a plesiomorphic characteristic, usually observed in the order Passeriformes and in other avian orders, demonstrating the conservation of the ancestral state (Figure 2F) (Nishida-Umehara et al., 2007; Oliveira et al., 2017; Santos et al., 2017).

In conclusion, we demonstrate that the morphology of macrochromosomes in C. lineata is significantly different from other Passeriformes species. Furthermore, we found a fission in GGA2, which appears to be a common chromosome rearrangement in Furnariidae and possibly other Parvorder Furnariida species that have minimal size difference between the first chromosomal pairs, in addition to the fissions that are typically found in Passeriformes (GGA1). However, since passerines present a high degree of chromosomal rearrangement, subsequent mapping and sequencing studies allowing the investigation of intrachromosomal rearrangements may elucidate these events.

\section{Acknowledgments}

The authors would like to thank the Group of "Diversidade Genética Animal" and laboratory "Cultura de Tecidos e Citogenética" SAMAM of the Evandro Chagas Institute for technical and financial support. CAPES and CNPq for the scholarships.

\section{Conflict of interest}

The authors have no conflicts of interest to declare.

\section{Author contributions}

RJG, EHCO, TDO conceived and designed the study; TDO, RK, NAB, PCMO, ADVG performed the experiments; TDO, RK, NAB wrote the manuscript; MAFS, PCMO English and critical review. All authors read and approved the final version.

\section{References}

Barbosa MDO, Silva RR, Correia VCDS, Santos LP, Garnero ADV and Gunski RJ (2013) Nucleolar organizer regions in Sittasomus griseicapillus and Lepidocolaptes angustirostris (Aves, Dendrocolaptidae): Evidence of a chromosome inversion. Genet Mol Biol 36:70-73.

Daniels LM and Delany ME (2003) Molecular and cytogenetic organization of the $5 \mathrm{~S}$ ribosomal DNA array in chicken (Gallus gallus). Chromosome Res 11:305-317.

Derjusheva S, Kurganova A, Habermann F and Gaginskaya E (2004) High chromosome conservation detected by comparative chromosome painting in chicken, pigeon, and passerine birds. Chromosom Res 12:715-723.

Ericson P, Irestedt M and Johansson U (2003) Evolution, biogeography, and patterns of diversification in passerine birds. J Avian Biol 34:3-15.

Ericson PG, Klopfstein S, Irestedt M, Nguyen JM and Nylander JA (2014) Dating the diversification of the major lineages of Passeriformes (Aves). BMC EvolBiol 14:8.

Griffin DK, Robertson LBW, Tempest HG and Skinner BM (2007) The evolution of the avian genome as revealed by comparative molecular cytogenetics. Cytogenet Genome Res 117:6477.

Guttenbach M, Nanda I, Feichtinger W, Masabanda JS, Griffin DK and Schmid M (2003) Comparative chromosome painting of chicken autosomal paints 1-9 in nine different bird species. Cytogenet Genome Res 103:173-184.

Itoh Y and Arnold AP (2005) Chromosomal polymorphism and comparative painting analysis in the zebra finch. Chromosome Res 13:47-56.

Kretschmer R, Gunski RJ, Garnero ADV, Furo IDO, O'Brien PCM, Ferguson-Smith MA and Oliveira EHC (2014) Molecular Cytogenetic Characterization of Multiple Intrachromosomal Rearrangements in Two Representatives of the Genus Turdus (Turdidae, Passeriformes). PLoS One 9: e103338.

Kretschmer R, Oliveira EHC, Dos Santos MS, Furo IDO, O'Brien PCM, Ferguson-Smith MA, Garnero A del V and Gunski RJ (2015) Chromosome mapping of the large elaenia (Elaenia spectabilis): Evidence for a cytogenetic signature for passeriform birds? Biol J Linn Soc 115:391-398.

Kretschmer R, Ferguson-Smith MA and Oliveira EHC (2018a) Karyotype evolution in birds: From conventional staining to chromosome painting. Genes (Basel) 9:181.

Kretschmer R, Lima VLC, Souza MS, Costa AL, O'Brien PCM, Ferguson-Smith MA, Oliveira EHC, Gunski RJ and Garnero ADV (2018b) Multidirectional chromosome painting in Synallaxis frontalis (Passeriformes, Furnariidae) reveals high chromosomal reorganization, involving fissions and inversions. Comp Cytogenet 12:97-110. 
Ledesma MA, Garnero ADV and Gunski RJ (2002) Análise do cariótipo de duas espécies da família Formicariidae (Aves, Passeriformes). Ararajuba 10:15-19.

Moyle RG, Chesser RT, Brumfield RT, Tello JG, Marchese DJ and Cracraft J (2009) Phylogeny and phylogenetic classification of the antbirds, ovenbirds, woodcreepers, and allies (Aves: Passeriformes: infraorder Furnariides). Cladistics 25:386-405.

Nanda I, Karl E, Volobouev V, Griffin DK, Schartl M and Schmid M (2006) Extensive gross genomic rearrangements between chicken and Old World vultures (Falconiformes: Accipitridae). Cytogenet Genome Res 112:286-295.

Nanda I, Karl E, Griffin DK, Schartl M and Schmid M (2007) Chromosome repatterning in three representative parrots (Psittaciformes) inferred from comparative chromosome painting. Cytogenet Genome Res 117:43-53.

Nishida-Umehara C, Tsuda Y, Ishijima J, Ando J, Fujiwara A, Matsuda Y and Griffin DK (2007) The molecular basis of chromosome orthologies and sex chromosomal differentiation in palaeognathous birds. Chromosome Res 15:721-34.

Oliveira EHC, Habermann FA, Lacerda O, Sbalqueiro IJ, Wienberg J and Müller S (2005) Chromosome reshuffling in birds of prey: The karyotype of the world's largest eagle (Harpy eagle, Harpia harpyja) compared to that of the chicken (Gallus gallus). Chromosoma 114:338-343.

Oliveira EHC, Moura SP, Anjos LJS, Nagamachi CY, Pieczarka JC, O'Brien PCM and Ferguson-Smith MA (2008) Comparative chromosome painting between chicken and spectacled owl (Pulsatrix perspicillata): implications for chromosomal evolution in the Strigidae (Aves, Strigiformes). Cytogenet Genome Res 122:157-162.

Oliveira EHC, Tagliarini MM, Rissino JD, Pieczarka JC, Nagamachi CY, O'Brien PCM and Ferguson-Smith MA (2010) Reciprocal chromosome painting between white hawk ( $\mathrm{Leu}$ copternis albicollis) and chicken reveals extensive fusions and fissions during karyotype evolution of accipitridae (Aves, Falconiformes). Chromosome Res 18:349-55.
Oliveira TD, Kretschmer R, Bertocchi NA, Degrandi TM, De Oliveira EHC, De Cioffi MB, Garnero ADV and Gunski RJ (2017) Genomic organization of repetitive DNA in woodpeckers (aves, piciformes): Implications for karyotype and ZW sex chromosome differentiation. PLoS One 12:e0169987.

Raikow RJ and Bledsoe AH (2000) Phylogeny and Ervolution of the passerine birds: Independent methods of phylogenetic analysis have produced a well-supported hypothesis of passerine phylogeny, one that has proved particularly useful in ecological and evolutionary studies. BioScience 50:487-499.

Ribas TFA, Nagamachi CY, Aleixo A, Pinheiro MLS, O'Brien PCM, Ferguson-Smith MA, Yang F, Suarez P and Pieczarka JC (2018) Chromosome painting in Glyphorynchus spirurus (Vieillot, 1819) detects a new fission in Passeriformes. PLoS One 13:e0202040.

Rodrigues BS, Kretschmer R, Gunski RJ, Garnero ADV, O’Brien PCM, Ferguson-Smith MA and Oliveira EHC (2017) Chromosome painting in Tyrant Flycatchers confirms a set of inversions shared by Oscines and Suboscines (Aves, Passeriformes). Cytogenet Genome Res 153:205-212.

Santos MDS, Kretschmer R, Frankl-Vilches C, Bakker A, Gahr M, O'Brien PCM, Ferguson-Smith MA and De Oliveira EHC (2017) Comparative cytogenetics between two important songbird models: The zebra finch and the canary. PLoS One 12:1-13.

Sasaki M, Ikeuchi T and Makino S (1968) A feather pulp culture technique for avian chromosomes, with notes on the chromosomes of the peafowl and the ostrich. Experientia 24:12921293.

Selvatti AP, Gonzaga LP and Russo CAM (2015) A Paleogene origin for crown passerines and thediversification of the Oscines in the New World. Mol Phylogenet Evol 88:1-15.

Associate Editor: Marcelo Guerra

License information: This is an open-access article distributed under the terms of the Creative Commons Attribution License (type CC-BY), which permits unrestricted use, distribution and reproduction in any medium, provided the original article is properly cited. 